\title{
Satisfação no parto normal: encontro consigo
}

\author{
The satisfaction of the normal delivery: finding oneself \\ Satisfacción en el parto normal: encuentro consigo mismo
}

GE Revista Gaúcha

de Enfermagem

\author{
Rafaela Camila Freitas da Silva ${ }^{a}$ \\ Bruna Felisberto de Souza ${ }^{b}$ \\ Monika Wernet ${ }^{b}$ \\ Márcia Regina Cangiani Fabbro ${ }^{\mathrm{b}}$ \\ Ana Carolina Belmonte Assalin ${ }^{a}$ \\ Jamile Claro de Castro Bussadori ${ }^{b}$
}

Como citar este artigo:

Silva RCF, Souza BF, Wernet M, Fabbro

MRC, Assalin ACB, Bussadori ICC. Satis-

fação no parto normal: encontro consigo.

Rev Gaúcha Enferm. 2018;39:220170218.

doi: https://doi.org/10.1590/1983-

1447.2018.20170218.

\footnotetext{
Universidade Federal de São Carlos (UFSCar), Departamento de Enfermagem. São Carlos, São Paulo, Brasil.

' Universidade Federal de São Carlos (UFSCar), Programa de Pós-Graduação em Enfermagem. São Carlos São Paulo, Brasil.
}

\section{RESUMO}

Objetivo: Compreender a satisfação da mulher na experiência do parto normal.

Metodologia: Estudo qualitativo, exploratório, descritivo, desenvolvido em janeiro e fevereiro de 2017, a partir de entrevista com vinte mulheres satisfeitas com o parir, residentes em município do interior de São Paulo. 0 Interacionismo Simbólico e Análise de Conteúdo Temática sustentaram o estudo.

Resultados: 0 tema central "Parto normal como encontro consigo", desenvolvido a partir de três unidades temáticas retratam a satisfação no parto normal: "Decisão pelo parto normal","Parto com suporte acolhedor";" "Violências: nem tudo são flores". A satisfação foi correlacionada com efetivação do desejo de parir, suporte acolhedor de doulas/profissionais de saúde e presença de acompanhante/ familiares no processo, mas também revela partos marcados por vivências invasivas, impositivas e não acolhedoras.

Conclusão: 0 empoderamento favorecido e sentido pela mulher na vivência do parto normal, reforça a premência de investimentos para efetivar transformações socioculturais que sustentam o nascer no Brasil.

Palavras-chave: Parto normal. Enfermagem obstétrica. Satisfação do paciente. Tomada de decisões.

\section{ABSTRACT}

Objective: To understand the satisfaction women experience during the normal delivery.

Methodology: Qualitative, exploratory and descriptive study, developed during January and February of 2017, from interviewing twenty women that were satisfied with their natural delivery, residing on the countryside of Sao Paulo. The Symbolic Interactionism and the Thematic Content Analysis support this study.

Results: The main theme "Normal delivery as a means to find oneself" developed through three thematic units that report the satisfaction in the normal delivery: "Decision for normal delivery", "Childbirth with welcoming support", "Violence: it is not all roses". The satisfaction has been correlated to the accomplishment of the dream of giving birth, welcoming support of Doulas/health professionals and the presence of a companion/family members during the process, but it also reveals labors marked by invasive, imposing and unwelcoming experiences.

Conclusions: The empowerment granted and felt by the woman during the normal delivery experience reinforces the urgency of investments to promote sociocultural transformations that concern childbirth in Brazil.

Keywords: Natural childbirth. Obstetric nursing. Patient satisfaction. Decision making.

\section{RESUMEN}

Objetivo: Comprender la satisfacción de la mujer en la experiencia del parto normal.

Metodología: Estudio cualitativo, exploratorio, descriptivo, desarrollado en enero y febrero de 2017, mediante entrevistas con veinte mujeres satisfechas con el parir, residentes en un municipio del interior de San Pablo. El Interaccionismo Simbólico y el Análisis de Contenido Temático sostuvieron el estudio.

Resultados: El tema central "Parto normal como encuentro consigo mismo", reflejado en tres unidades temáticas, que aborda la satisfacción en el parto normal: "El optar por el parto normal", "Parto con soporte acogedor"; "Violencias: no todo son flores". La satisfacción fue correlacionada con la efectividad del deseo de parii, soporte acogedor de doulas/profesionales de salud y presencia de acompañante/familiares en el proceso, pero también revela partos marcados por vivencias invasivas, impositivas y de no acogida. Conclusión: El empoderamiento favorecido y sentido por la mujer en la vivencia del parto normal refuerza la urgencia de inversiones para efectuar transformaciones socioculturales que sostienen el nacer en Brasil.

Palabras clave: Parto normal. Enfermería obstétrica. Satisfacción del paciente. Toma de decisiones. 


\section{—INTRODUÇÃO}

Sob o enfoque de gênero, as práticas e o modelo de assistência obstétrica em vigência no Brasil ainda efetiva desrespeitos e ignora ou subvaloriza direitos sexuais, reprodutivos e humanos ${ }^{(1-3)}$. Há altos índices de cesárea e maus tratos as mulheres nas maternidades brasileiras ${ }^{(1)}$, com desestímulo ao parto normal (PN) e relatos de mulheres de não satisfação da mulher diante do parto vivenciado(2).

O modelo de saúde vigente, médico centrado, institucionalizado, valorizador da patologia e com primazia da tecnologia assistencial sobre as relações humanas, contribui com os apontamentos acima. Esse aspecto soma-se ao entendimento de não ser a mulher capaz de parir, com repercussões à efetivação de seu protagonismo(3).

Há cerca de 30 anos, reflexo da visibilidade da situação descrita cima, iniciativas da Organização Mundial da Saúde (OMS), políticas indutoras nacionais e internacionais impulsionam lutas para transformação deste cenário. O Brasil vem participando de movimentos desta natureza, com esforços de aumentar a consciência sobre a situação e promover ações relativas à gestações e partos mais seguros para as mulheres e os recém-nascidos. No entanto, muitas são as insuficiências na prática assistencial, sobretudo em termos de valorização de intervenções profissionais e desrespeito aos valores das mulheres e de suas famílias ${ }^{(3-4)}$.

Como consequência, o índice de cesarianas desnecessárias no Brasil é tomado enquanto uma 'epidemia'(3). Os resultados de uma ampla pesquisa, "Nascer no Brasil: Inquérito Nacional sobre Parto e Nascimento", coordenada pela Fundação Oswaldo Cruz (Fiocruz) ${ }^{(3)}$ que reuniu informações de 23.940 mulheres atendidas entre fevereiro de 2011 e outubro de 2012, em 266 maternidades com 500 ou mais partos por ano, de 191 municípios brasileiros, confirmaram ter sido $52 \%$ dos nascimentos por cesariana. No setor privado, este número sobe para $88 \%$, conferindo ao Brasil o título de líder em cesárea no mundo.

Violências neste âmbito culminam em violação dos direitos de mulheres e crianças, quando negativas de informação tem sido reincidente ${ }^{(5-6)}$, com violação dos direitos reprodutivos, comprometendo a escolha esclarecida e consciente sobre a via de parto, bem como a oferta de um cuidado digno ${ }^{(7)}$. A escolha da cesárea como parto ideal perpassa esta negativa e/ou omissão nas práticas assistenciais (5-6).

Muito tem se discutido sobre formas de qualificar a atenção obstétrica e a aposta tem sido de ênfase e retomada do protagonismo feminino/familiar no nascimento, com visibilidade e densificação de evidências científicas acerca de danos e violações no contexto do parto e nascimento. Além disso, o horizonte tem sido de divulgação dos pressupostos de uma atenção humanizada no parto, e a necessidade de não se restringir o parto a um "processo biológico", e, sim enquanto "evento humano"(4).

O presente estudo incorpora-se ao movimento de garantir os direitos reprodutivos da mulher e consequente satisfação materna ${ }^{(6)}$, sob a pergunta de "Quais fatores estão relacionados à escolha do $\mathrm{PN}$ e quais estão associados à satisfação das mulheres com o processo de parto? ". O objetivo foi de compreender a satisfação da mulher diante da experiência do PN. Espera-se com ele proporcionar aos profissionais da saúde, reflexões relacionadas à compreensão das necessidades da mulher no processo e alicerces para um cuidado pautado na humanização, protagonismo feminino e proteção de direitos.

\section{METODOLOGIA}

Estudo qualitativo, exploratório e descritivo, apoiado no referencial do Interacionismo Simbólico (IS), por reconhecer as interações sociais enquanto espaços de estabelecimento de entendimentos com implicações às ações sociais( ${ }^{(8)}$.

Foi desenvolvido em um município de médio porte do interior do estado de São Paulo que dispõe de uma área de abrangência de $1.137 \mathrm{~km}^{2}$, com população estimada de 246.088 habitantes $^{(9)}$. No ano de 2015 ocorreram 3.235 nascimentos no município, destes, 882 (27.7\%) foram PNs ${ }^{(10)}$.

A atenção à saúde no ciclo gravídico-puerperal de risco habitual da cidade conta com o serviço das Unidades Básicas de Saúde (UBS), Unidades de Saúde da Família (USF) e uma maternidade, alocada em um hospital filantrópico. O município conta com iniciativas autônomas de enfermeiras e doulas na oferta de grupos de apoio ao parto.

O convite e localização das mulheres ocorreu a partir de postagens em rede social, de cartazes afixados em unidades de saúde do município e nos grupos de apoio. Os critérios de inclusão ao estudo foram: ter idade maior ou igual a 18 anos ou ser emancipada, terem tido parto normal e se declararem satisfeitas com a experiência de parir. No total 21 mulheres entraram em contato, no entanto, uma foi excluída por não ter vivenciado o parto normal na cidade do estudo. Todas as participantes assinaram o termo de Consentimento Livre e Esclarecido.

A coleta dos dados ocorreu no período de janeiro a fevereiro de 2017, por meio da aplicação de um questionário voltado a caracterização sociodemográfica e obstétrica, seguida de entrevista aberta disparada pela colocação:" Você afirmou ter tido satisfação com o seu parto. Conte-me, como foi viver essa experiência?" Ao longo das entrevistas outras questões foram apresentadas, de forma articulada à narrativa da participante com vistas a ampliar a compreensão do exposto. A 
duração das entrevistas foi de cerca de 21 minutos cada. Ressalta-se que a coleta de dados foi encerrada quando os dados passaram a apresentar repetição e redundância, sem revelação de novos elementos ao fenômeno em estudo(11).

Todas as entrevistas foram gravadas em áudio e transcritas em sua íntegra, sofrendo apenas correções estruturais, sem modificar o sentido do que foi expresso pelas entrevistadas. Os dados extraídos das entrevistas foram analisados a partir da análise de conteúdo temática ${ }^{(12)}$. Cada entrevista sofreu leituras flutuantes para apreensão da experiência narrada, com atenção a significados e ações envolvidas no fenômeno de parir com satisfação. Após este procedimento, novas e reiteradas leituras foram desenvolvidas, quando se identificaram blocos textuais tematicamente, que em momento analítico e interpretativo subsequente foram integrados. A partir deste processo identificou-se enquanto tema central "Parto normal como encontro consigo", derivado das três unidades temáticas, a partir das quais os resultados estão apresentados: "Decisão pelo parto normal"; "Parto com suporte acolhedor" e "Violências: nem tudo são flores".

Todas as recomendações éticas para pesquisas com seres humanos foram seguidas. A pesquisa foi aprovada por Comitê de Ética em Pesquisa em Seres Humanos, com parecer consubstanciado registrado sob o número 1.753.086, de 29/09/ 2016.

\section{- RESULTADOS E DISCUSSÃO}

Dentre as 20 mulheres que participaram do estudo, a média de idade foi de 30 anos, sendo a 19 anos a menor idade e 43 anos a maior idade. Setenta porcento das mulheres se auto referiram de cor branca, $75 \%$ casadas, $45 \%$ possuíam pós-graduação, $60 \%$ realizavam atividade remunerada fora do lar e a renda média familiar era de 5,7 salários. A maioria era primigesta (55\%) e primípara (65\%), 55\% das gestações tinham sido planejadas, com o início do acompanhamento de pré-natal por volta da sexta semana de gestação. Quase a totalidade das mulheres realizou um total de 10 consultas de pré-natal, em sua maioria (70\%) no setor suplementar. Das gestações referência, duas foram gemelares. Dos partos, 19 foram hospitalares e 01 domiciliar planejado. A amamentação na primeira hora de vida do bebê foi referida por $65 \%$ delas. Destaca-se um perfil de mulheres com condições diferenciadas ao acesso e à assistência em saúde, são a maioria brancas, economicamente estáveis, que foram assistidas em se pré-natal e parto pela rede suplementar.

As mulheres deste estudo ressaltam enquanto essência da experiência de parir com satisfação o encontro com seu íntimo, com seu interior, reveladora de toda a sua potencialidade e capacidade enquanto mulher, chegando a ser apontada como um renascimento e de grande intensidade. Desta forma, o"PN como encontro consigo" retrata a experiência vivida no PN quando a satisfação se fez presente.

[...] eu nunca me senti tão bem quanto mulher, eu me senti um bicho...um bicho! Tipo, eu me senti...foi incrivel chegar tão perto da natureza. É isso. Eu nunca me senti uma potência tão gigantesca. (E7)

[...] fo foi a melhor experiência da minha vida. Tanto que no outro ano eu já tive meu outro filho [...] é uma experiência, nossa...maravilhosa, maravilhosa! Eu falo que toda muIher tem que passar, porque é muito bom! (E9)

Foi assim, uma experiência maravilhosa, você passa se conhecer mais...é uma experiência assim, enquanto mulher, enquanto mãe...assim, eu nasci de novo, sabe. (E19)

[...] eu me senti muito forte de conseguir, sabe, é...você se sente mulher mesmo, na raiz sabe. Consegui é...além de gerar, parir! (E11)

\section{Unidade temática 1: Decisão pelo parto normal}

A decisão pelo PN tem o com desejo latente por viver o mesmo como estruturante. Esse desejo articula-se com a valorização do processo de parir, do caráter'natural' presente nele e dos benefícios que ele provê, tanto para a mulher, quanto para o bebê. Significam-no enquanto capacidade que todo animal tem de parir, inclusive os humanos.

[...] eu sempre quis ter parto normal. Sempre pensei que se tivesse um filho, ia ser normal. (E2)

É algo natural, é o que está ali. Fui ali, pari, tive um bebê, estou aqui! É algo natural, que está no nosso sangue...é nosso. Nós somos bichos também e esquecemos disto. (E4)

Ah, a própria palavra fala. "Normal". É normal isso. É da nossa natureza, parir. Eé a melhor coisa que tem na vida colocar uma criança no mundo, nossa. É muito gostoso. (E9)

Integra a efetivação do desejo e da persecução a ele terem compartilhado em seu contexto social vivencias positivas, que revelaram beleza e valores. Estas situações atuam enquanto epifanias, sedimentando a certeza de ser o que elas desejavam para si e sua criança, antes mesmo da gravidez.

[...]eu decidi na adolescência. [...] uma professora estava falando de parto na banheira [...] e eu pensei, é isso que eu quero! (E10) 
Acho que mais...referência à minha mãe. Minha mãe teve 3 partos normais. (E2)

Outro elemento que está ponderado na decisão pelo PN diz respeito ao medo da cesariana e os riscos identificados nela, quando decidem que irão vivenciá-la apenas na necessidade.

Desde a primeira gravidez eu sempre soube que eu queria um parto normal[...] e dessa gravidez eu também sempre quis. Tenho muito medo de fazer uma cesárea. (E12)

[...] tinha muito medo de precisar de uma cesárea [...] e todos os riscos que a cesárea oferece, que quase ninguém conhece [...] é uma cirurgia importante, mas só quando é necessária. (E17)

Identifica-se, pelo exposto, que as mulheres deste estudo articularam reflexões que perpassam o significado da cesariana e do PN, quando este último foi adjetivado como natural, inerente à capacidade humana. Estas construções foram socialmente estabelecidas e agiram enquanto epifanias. Esse aspecto é um avanço promovido por este estudo, na direção de se fazer apostas intencionais e estruturadas do compartilhamento em espaço social de vivências positivas com o PN, assim como fazer uso delas quando presentes junto a experiências de familiares.

Apostas na divulgação de experiências positivas com o PN pode vir a contribuir com a não ocorrência de cesarianas desnecessárias e todos os riscos inerentes a esta cirurgia, reduzindo desfechos negativos, e repercussões à morbimortalidade materna e neonatal(3). Esta parece ser esta uma entrada de significado e sensibilização que pode se somar a entradas que apostam nas discussões dos benefícios e riscos de cada tipo de parto.

O medo da cesariana em termos de seus riscos ${ }^{(12)}$ integrou a decisão pelo PN, juntamente com a valorização do processo 'natural'(6,12) como aparece em estudos neste âmbito.

As questões da dor, comum em estudos sobre PN e cesarianas ${ }^{(12-13)}$, foi aqui apresentada de forma peculiar: significaram a vivencia da dor do parto como integrante da experiência do PN, existindo aquelas que a conceberam como a concretude da chegada do filho e, outras com a curiosidade de dimensioná-la diante da cultura negativa socialmente disseminada.

Ai, eu queria muito. Falei, nossa, não é possível que eu vou passar essa vida sem ter normal, para ver o que é a dor. (E3)
Eu sempre tive aquilo em mente assim, eu quero saber se essa dor é tudo isso mesmo que todo mundo diz que é. (E4)

Então foi isso que eu quis, entendeu. Eu quero sentir a dor do parto, eu quero sentir meu filho chegando. (E20)

As mulheres devem ser esclarecidas sobre a questão da dor e trabalho de parto, que de fato ela é real, assim como no pós-operatório de uma cesárea, e, de modo similar, há formas de ser amenizada ${ }^{(12,14)}$. Experienciar a dor do trabalho de parto é um processo complexo e variável de mulher para mulher, contudo, todas detém capacidade de se adaptar ao evento doloroso ${ }^{(15)}$. Trata-se de experiência única, individual e subjetiva, que agrega valor para o trabalho de parto e o tornar-se mãe(14) , ideia similar a encontrada no presente estudo.

A dor no PN é comumente explorada por profissionais para coagir mulheres a optarem pela cesariana, em conjunto com a ideia da segurança provida pela mesma(16). As muIheres deste estudo não trouxeram ter sofrido este tipo de abordagem, muito provavelmente pela segurança e certeza demonstrada com a opção pelo PN e o pacto interno que possuíam em fazer esforços para vivenciar o mesmo. Isto remete a reflexões em relação a socialização e o como o PN vem sendo movimentado na direção de ser processo para o qual todas as mulheres detêm capacidade, assim como podem vir a contar com suporte profissional para transpor momentos críticos que venham a integrar o processo.

Apostas nesta direção, minimizarão desconfortos decorrentes de atos cirúrgicos desnecessários, como são as cesáreas eletivas, assim como ampliarão a ocorrência de amamentação na primeira hora de vida do bebê diante da cesariana(17) , a formação de vínculo e apego, a parentalidade, diante das oportunidades e proteção do contato íntimo entre pais e filhos. Ou ainda, redução de taxas de prematuridade, de dificuldades em amamentar e de complicações obstétricas, desfechos com íntima articulação com cesarianas ${ }^{(3,17)}$.

A opção pelo PN contém ainda a busca de informações sobre o mesmo, quando apreciam relato de mulheres e casais que o vivenciaram, sobretudo via leituras e/ou apreciação de documentários sobre o tema. Esta ação faz traz crítica sobre os aspectos socialmente difundidos em relação ao PN, quando identificam tendenciosidade. Assim, tais contatos fortalecem e reforçam a tomada de decisão, com destaque a relevância de se buscar esclarecimento sobre o PN e profissionais que de fato se alinhem com o mesmo. Apontam ser dever dos profissionais na assistência gravídico puerperal ofertar informações claras e corretas sobre o PN e a cesariana, com vistas ao desenvolvimento da segurança para se vivenciar o processo do PN. 
Porque sem informação você não consegue nada, você fica insegura pelas coisas que você ouve por aí. Se eu fosse seguir o que eu ouvi, não faria parto normal não. (E6)

Eu indicaria ir atrás de informações, leis, estudar tudo que fosse é...pertinente. E procurar uma equipe que esteja pensando na mesma maneira, se não vai por água abaixo. (E1)

Estes achados corroboram com estudos que demonstraram que a decisão pela via de parto é fortemente influenciada por vivências e experiências próprias anteriores, bem como por fatores externos, como os relatos de outras mulheres e informações recebidas por fontes diversas ${ }^{(6,18)}$. $O$ veiculado no entorno social integra a decisão pelo $\mathrm{PN}$, O que implica ao profissional de saúde o compromisso em dar visibilidade e acessibilidade às informações relativas ao PN, favorecendo discussões nas diversas ferramentas assistenciais como visitas domiciliares, consultas, grupos, ações educativas, desmistificando mitos e tabus. Nestas últimas pode fazer uso de produções audiovisuais de acesso gratuitos.

Quantos aos meios de informações, os documentários foram mencionados como potentes fontes, capazes de influenciar a visão sobre o PN, visto que trazem relatos e imagens, por vezes, impactantes, além de exporem os diversos benefícios da experiência ${ }^{(6,12-13,18)}$, como é demonstrado na fala da entrevistada abaixo, refletindo o impacto que uma boa fonte de informação pode exercer, influenciando diretamente na tomada de decisão.

Meu marido alugou um filme, o Renascimento do Parto. E... a gente começou a assistir e a gente começou a se ver no filme. [...] foi nesse filme que caiu minha ficha que eu tinha tudo para ter um parto normal, [...] então veio dessa vontade. (E6)

Encontrar apoio informacional, principalmente sobre a fisiologia do parto, através de diversas fontes como grupos de apoio, consulta do pré-natal e outros, foi essencial para a confiança em sua capacidade de parir, refletindo em felicidade e plenitude com a experiência. Esse processo vivenciado durante a gestação, reflete um empoderamento necessário das mulheres, capaz de dar sentido ao ser mulher e ao PN, fortalecendo e preparando-as para o parir.

[...] eu acho que acreditar no corpo. A ter aprendido a acreditar na fisiologia do parto, do corpo, nesse preparo pré-parto, o conhecimento de si mesma, do corpo, que vai levar a mulher, a entender aquilo que está acontecendo com ela naquele momento do parto. (E4)
[...] frequentei um grupo de apoio mesmo. Eu ia nos relatos de parto. Ever as mulheres que passaram por isso contando...estavam vivas, estavam bem, tipo, "oh...foi ótimo". Isso...me deixou muito consciente, na hora, do que eu estava fazendo e por isso eu estava muito segura. (E11)

[...]o pré-natal é fundamental, a preparação, os degrauzinhos que você vai sendo preparada, eu acho que é fundamental. [...] A minha médica é... ela é incrivel. Chegava lá com 100 dúvidas e as 100 dúvidas ela me tirava. [...] então eu acho que o pré-natal realmente é o ponto chave da situação. Acho que ele ajuda bastante. (E16)

Dar visibilidade a informação sobre o PN, tanto no âmbito de sua fisiologia, quanto da experiência em si precisa estar na agenda dos profissionais de saúde, com vistas ao desafio de desconstruir o entendimento da mulher pouco (in)capaz de parir ${ }^{(2-4,6,18)}$.

Desta forma, através das falas evidencia-se o poder da educação em saúde em resgatar a confiança nas mulheres na sua capacidade de parir. Estudo aponta que a preparação para o parto, através da instrumentalização para o processo, torna as mulheres mais confiantes e seguras de que seus corpos são capazes, e ao serem protagonistas, vivenciam uma experiência satisfatória ${ }^{(18)}$. Ainda, a autonomia das gestantes, adquirida através de informações, está prevista na prevenção quaternária da violência obstétrica $(\mathrm{VO})^{(7,18-19)}$. Cabe ressaltar que a desinformação está entre os fatores que sustenta a ideia da cesárea como parto ideal( ${ }^{(6)}$.

\section{Unidade temática 2: Parto com suporte acolhedor}

O trabalho de parto foi vivenciado enquanto evento rápido, transposto de forma mais fácil do que imaginado por elas.

Foi muito rápido, mais fácil do que a gente pensa, que é um bicho de sete cabeças [...] (E6)

[...] foram mais algumas contrações e ele nasceu, foi bem rápido, eu não estava esperando, eu estava esperando que iria demorar muito mais... (E17)

A superação das expectativas relatada, foi capaz de consolidar a visão positiva delas sobre o PN. Fizeram a opção pelo mesmo e estavam dispostas a vivenciá-lo, mas tinham em reflexão os diversos apontamentos negativos socialmente exaltados. Assim, destaca-se a importância de compartilhar histórias de sucesso no PN para outras mulheres, 
desde sempre, ao longo da gestação, bem como no âmbito das conversas informais em família e amigas. Cuidar para que desde a infância ocorra uma socialização que dê a oportunidade de perceber e significar o PN positivamente é fundamental. Dessa forma, haverá elementos para fazer contraponto aos comuns apontamentos negativos que tentam coagir mulheres a optar de antemão pela cesariana.

Um dos aspectos ressaltados pela maioria das mulheres deste estudo foi a rápida recuperação no pós-parto, com implicações a pronta condição para cuidar de si, da criança e desenvolver atividades diárias. Este aspecto trouxe satisfação.

[...] o pós-parto também foi maravilhoso, porque eu não tive intercorrência nenhuma, né. Ele acabou de nascer eu já pude levantar, então é... a experiência pra mim foi muito boa. (E1)

E a recuperação, como falam, é ótima. [...] meu pós-parto foi excelente. [...] porque a recuperação é ótima, pós-parto ébom, vocêjá pode pegar teu filho... (E13)

A recuperação, sabe, dentro de casa...na minha questão, que eu já tinha uma filha, então eu precisava dessa recuperação mais rápida sabe. [...] então a recuperação do parto normal é maravilhosa. (E16)

A vivência dessas mulheres está em consonância com relatos de outras em termos de uma melhor e mais rápida recuperação, não tendo as complicações inerentes a uma cesárea, com retorno quase que imediato à rotina diária ${ }^{(19)}$.

Ainda que tenham experienciado a dor no processo de parir, esta não ficou marcada enquanto um elemento negativo na memória das mulheres. Prospectar a proximidade de contato com sua criança e a felicidade que sentiriam diante disto, contribuiu com o enfrentamento positivo da situação. Apontam que no período expulsivo, o quadro álgico passa a ficar ausente.

[...] quando passa a contração você não sente nada, é como se você não tivesse nem sentido a contração. (E18)

Sempre pensar que depois daquela dor, já vem a nossa felicidade, tudo vai valer a pena. (E9)

[...] eu lembro das dores, né, hoje falando, mas não lembro de sofrimento nenhum. [...] é uma dor, mas como eu disse não é sofrimento. [...] no período expulsivo, por exemplo, eu não senti dor nenhuma. A partir do momento que eu entrei no período expulsivo, já não senti mais dor nenhuma. (E1)
A opção de algumas mulheres pela cesárea tem correlação com o reforço sociocultural sobre o PN ser uma experiência dolorosa ${ }^{(12-13)}$. Porém, é importante ressaltar que a dor se faz presente em ambas as vias de nascimento, mas no PN seu alívio ou redução é bem alcançado por meio do uso das Técnicas Não-Farmacológicas de Alívio da Dor (TNFAD) ${ }^{(15)}$.

Há práticas que favorecem tranquilidade e satisfação no PN, como a presença ativa de acompanhante, suporte contínuo, atendimento empático e respeitoso da parte dos profissionais de saúde, informação contínua ao longo do processo, presença da enfermeira obstetra (EO), uso de TNFAD, promoção do contato pele a pele com o bebê, entre outras. A presença do acompanhante, independentemente de quem tenha sido, foi reconhecida como fundamental para que pudessem lidar com medos e angústias e passar com tranquilidade pelo trabalho de parto e parto, revelando-se como um componente central na satisfação diante o PN.

[...] eu tinha meu marido junto comigo. [...] acho que se eu não tivesse o apoio dele, não teria sido satisfatório. (E1)

[...] o meu marido comigo o tempo todo...ficou ali comigo o tempo todo e foi ótimo assim, a gente ficou super conectado e foi bem legal. Ele fala muito pouco, continuou falando muito pouco, mas me apoiava quando precisava me apoiar. (E7)

Ter um acompanhante no parto é uma prática que está de acordo com a Lei do Acompanhante e com diretrizes que a determinam como um direito ${ }^{(20)}$, sustentados por estudos que demonstram forte relação entre a presença do acompanhante e satisfação com o parto, mesmo quando está sob condições não favoráveis ${ }^{(14,18-20)}$. Além disso, tal garantia proporciona conforto e apoio emocional contínuo, como oferta de métodos não-farmacológicos de alívio da dor, facilita contato pele-a-pele, transmite segurança e auxilia na inibição de adoção de práticas não recomendadas e prejudiciais às mulheres e aos recém-nascidos $(\mathrm{RN})^{(7,20)}$.

Em adição, a presença de familiares no momento do parto é quista e considerada essencial para o estabelecimento e fortalecimento de vínculos entre os membros, com desdobramentos positivos à futura relação com a criança.

E ela [filha] e meu marido assistiram a neném nascer. E foi do jeito que eu queria, ela não me atrapalhou e viu a irmã nascer. Eu queria que ela [filha] visse, queria que ela (filha) acompanhasse. (E4)

Mas ele [marido] também diz que foi maravilhosa a experiência de acompanhar tão de perto. Ele [marido] tem um 
vínculo com a nossa filha que eu acho impressionante. Eu tenho certeza que aquilo fortaleceu a relação. (E7)

E foi muito importante para o meu companheiro também, nós dois como casal, passar por isso junto, sabe, ver como ele se entregou de corpo e alma. (E19)

Este resultado corrobora com estudos que demonstram a importância e o benefício da presença de um acompanhante no processo de parturição(16,18-20). Estudo internacional realizado em uma unidade hospitalar que proíbe parcialmente a participação dos familiares, demonstrou que, ainda que as mulheres prefiram estar acompanhadas pelos seus familiares, sentem-se satisfeitas com a companhia de profissionais de saúde, sobretudo quando o cuidado ofertado é compreensivo e humanizado, pois consideram como uma forma de não sentirem-se sozinhas ${ }^{(14)}$.

O suporte contínuo, seja por Doulas ou profissionais de saúde, também esteve associado à satisfação, aconchego, apoio e estímulo, chegando até mesmo a tecerem paralelo com o suporte materno.

[...] aí ela [Doula] chegava perto de mim assim, me abraçava...me ajudou muito. [...] quando elas [Doulas] chegaram elas [Doulas] ficaram o tempo todo comigo, me abraçando, me dando água, perguntando como que eu estava, tipo igual uma mãe ficaria. O tempo todo. (E3)

Eu assim, eu falo, é...eu não tenho, não sei nem descrever assim o tanto que é importante uma doula no parto, no dia do parto, na hora do parto. [... A doula, que foi assim para mim foi...foi o que...foi juntando tudo que me deixou muito satisfeita com o parto. (E13)

Nesta mesma direção, estudos apontam que este apoio é melhor quando provido por alguém que não é do meio social da mulher e nem da equipe de saúde, mas por uma pessoa que está ao lado da mulher com a função de apoiá-la ${ }^{(17,19)}$, como é o caso de Doulas. Isto pode demonstrar a abrangente dimensão da importância de sua presença, muitas vezes menosprezada culturalmente.

Outro fator importante para a satisfação foi a condução do parto por EOs. As mulheres associam o mesmo a atos mais humanizados, a apoio informacional e técnico contínuos, repercutindo em confiança e segurança no parto. Pode-se perceber através das falas abaixo, que elas reconhecem a importância deste trabalho, reforçando que a assistência profissional vai além do modelo médico-centralizado.

[...] eu acho que precisa mesmo de mais enfermeira obstetra [...] e eu acho que fortalece muito essa parte do lado humanizado. Porque as pessoas falam tanto de médico, médico, e eu acho que a enfermeira é tanto quanto importante. (E6)

[...] uma enfermeira obstetra, eu não abriria mão, porque ela sabe de todos os caminhos. Uma pessoa que pode te tocar, auscultar seu bebê, que pode te deixar tranquila que tudo está indo bem, que está dando certo [...] eu acho que é importante você ter uma pessoa que você confia, te guiando. Eu falo que assim, eu não abro mão da enfermeira que me acompanhou. (E8)

A importância da assistência prestada por EO's também foi identificada em outros estudos como sustentação de uma vivência de parto mais prazerosa, pois promove diminuição da ansiedade, do medo e até mesmo da dor do processo ${ }^{(15)}$, além de preventiva a VO ${ }^{(5,7,20)}$. EO's também aplicam com maior frequência as TNFAD ${ }^{(15)}$, preconizadas em diretrizes ${ }^{(5,20)}$ e identificadas pelas entrevistadas como benéficas.

Eu sei que a gente usou vários métodos. Usei a bolsa, usei o chuveiro...tanto a doula quanto meu marido fizeram massagem, isso ajudou bastante para aliviar. Mas eu acho que o que mais me ajudou foi o cabo de guerra. Aquilo foi fantástico. (E10)

[...] eu fiquei no chuveiro, a água alivia demais, é impressionante. Ai encheram a banheira e fui para a banheira, tentei ficar na banheira até para descansar um pouco porque estava muito intenso, e foi muito bom... (E17)

O uso das TNFAD têm se mostrado importante para minimizar a dor durante o trabalho de parto, tornando o processo mais fácil e garantindo energia para a hora do nascimento(15). Além disso, quando os profissionais reconhecem e respeitam a fisiologia do parto, colocam essas técnicas à disposição das mulheres para elas escolherem o que preferem ou acharem melhor, de acordo com a sua necessidade e vontade, promovendo assim a liberdade e a autonomia das parturientes com seus corpos(5).

A oportunidade do contato imediato com o filho desponta-se como uma necessidade acolhida no PN. O momento é lembrado com riqueza de detalhes e intensos sentimentos.

Veio direto para o meu colo. Eu lembro que eu estava super curiosa para ver aquele rostinho, lembro que eu contei os dedinhos dele [...] e foi, nasceu empelicado. Até me arrepio! Peguei ele no colo, aquele pacotinho, aquela coisa linda. (E10) 
[...] foi um momento maravilhoso, eu não tenho palavras para descrever, porque ter ele nos braços, calminho, ele olhava tudo que estava acontecendo, reconhecendo aquele ambiente novo para ele... (E17)

O contato pele a pele com a mãe na primeira hora de vida do RN é uma conduta já preconizada em diretrizes nacionais, com benefícios biológicos ao binômio ${ }^{(20)}$, bem como ao vínculo, garantindo maior satisfação com o momento $^{(3)}$. Elas emocionavam-se ao narrar o momento, com riqueza de detalhes e demonstrando intensos sentimentos em relação ao mesmo. Assim, foi identificado que este primeiro contato é um dos momentos mais intensos e marcantes da parturição.

\section{Unidade temática 3: Violências: nem tudo são flores}

Apesar da satisfação relatada pelas mulheres, critério de inclusão deste estudo, vivências invasivas, impositivas e de não acolhimento, estiveram presentes na experiência de algumas delas, configurando-se em VO's, ainda que anteriormente elas tivessem afirmado que estavam felizes e satisfeitas.

[...] e aí já tinha virado uma coisa de louco porque todo mundo que entrava ali enfiava a mão em mim. Todo mundo queria entender porque que aquele neném não nascia logo. [...] Então eu já tinha virado maçaneta ali. Todo mundo colocava a mão, sabe. (E19)

[...]eu pedi para deixar ali no quarto mesmo. Ele (médico) falou não. [...] Ai deitei naquela cama horrivel, que se tem que ficar reta, que dá aquela vontade enorme de vocêsentar, ou...curvar para frente. E ele falou para eu ficar ali. (E2)

[...] eu pensei que eu ia chegar no hospital, ia ficar com as pernas abertas, e o médico ia ficar tipo, dando corte. Eu morria de medo de levar corte, para poder sair o neném, na hora de puxar, ficava com muito medo deles, sei lá, não tinha noção de como que era. Eu estava com muito medo. Disso ninguém conversou lá no hospital. (E3)

Pesquisas apresentam evidências de diversos tipos de maus tratos e alta prevalência de VO que as mulheres sofrem durante o parto, que dificultam a plena satisfação com este momento ${ }^{(1,13)}$. A continuidade das práticas e intervenções não recomendadas que se traduzem como VO, contribuem e fortalecem a visão negativa sobre o PN, levando algumas mulheres a optarem pela cesárea, pelo medo de vivenciar um parto intervencionista e doloro$\mathrm{so}^{(3,7,78-19)}$. A filosofia do PN precisa ser um compromisso do profissional que está a apoiar o processo de parir/nascer ${ }^{(13)}$.

A alta frequência da $\mathrm{VO}$ a banalizou, dado que ela é vista pelo profissional de saúde como inerentes as seus atos e condutas institucionalizados, pautados em rotinas hospitalares, que são vistas como esperadas. Persiste uma assistência onde prevalece o uso do poder e a ocorrência da dominação simbólica, submissão, subordinação, autoritarismo, negligência e impessoalidade com os aspectos emocionais e relativos ao cuidado no pré-parto, parto e pós-parto imediato, resultados de uma revisão da literatura sobre o tema ${ }^{(1)}$. A alta frequência da $V O$ banalizou também a sua ocorrência de forma que mulheres já esperam vivenciá-las no PN, fato que contribui para que as mulheres deste estudo se mantivessem autorreferindo satisfeitas, mesmo diante de VO.

Elas se incomodaram com os atos típicos da VO, porém o comportamento foi de evitar confronto, de obediência e passividade ${ }^{(19)}$, em especial quando assistida em serviço público.

[...] a minha intenção era não deixar ele (médico) irritado. [...] Porque eu sabia como funcionava o esquema do SUS, a troca de plantão, já tinham me informado de uma coisa que eu nem sabia que existia isso. Pensei que eu que decidia o que eu queria. Aí eu deixei por [ocitocina]. (E2)

Por que isso acontece? Historicamente as mulheres são objetos das práticas de saúde autoritárias, assim como culturalmente aceitam o que lhe é oferecido, sem grandes questionamentos, o que nos faz refletir na importância de discutir a socialização de gênero, que nos incute a ideia de fragilidade e passividade ${ }^{(2)}$.

A prevenção da VO é desafio contemporâneo que perpassa por incorporar na assistência ao parto, práticas cientificamente comprovadas como benéficas e resolutivas ${ }^{(1,2,7,13)}$.

Este estudo analisou a satisfação e a decisão pelo parto normal em uma realidade específica e teve enquanto participantes mulheres de condição socioeconômica diferenciada. Recomenda-se estudos que explorem a satisfação no PN junto a participantes de outras características, com vistas a favorecer a dialogar com os achados deste estudo e ampliar o entendimento da satisfação no PN. Por exemplo, "Como está caracterizada a experiência de satisfação no PN de mulheres em contextos de vulnerabilidade social? E entre as adolescentes?".

\section{- CONCLUSÕES}

Para as mulheres deste estudo, a decisão e desejo de PN foi processada a partir de interações sociais favorecedoras 
de um interesse e busca em conhecer o PN. Este processo envolve a contraposição de apontamentos sociais típicos sobre PN e cesariana com as revelações que obtém a partir de suas buscas e reflexões acerca do PN. Na vivência do PN reforçam os valores que ponderavam ao mesmo e valoram sua representatividade para o ser mulher. Destacam ser uma prática obstétrica humana, valorizadora da singularidade, direitos e protagonismo.

Aos profissionais de saúde e enfermeiros aferem a relevância de socializar na direção de significar o PN como natural, possível a toda mulher e promotor de vivencias positivas, com apostas na publicização de experiências de pessoas que o vivenciaram. Àqueles que conduzem o PN, fazer apostas e uso de estratégias para a promoção do conforto e assistência livre de danos, com indicação de EO's e obstetrizes para sua condução.

De forma global, o presente estudo promoveu reflexões e tem potencialidade para estimular os profissionais de saúde a buscarem inovações que se alicercem em um cuidado pautado na humanização do parto, no protagonismo feminino e na proteção de direitos humanos.

\section{口 REFERÊNCIAS}

1. Barbosa LDC, Fabbro MRC, Machado GPR. Violência obstétrica: revisão integrativa de pesquisas qualitativas. Av Enferm. 2017 [citado 2017 set 20];35(2):190207. Disponivel em: http://www.scielo.org.co/scielo.php?script=sci_ arttext\&pid=S0121-45002017000200190\&lng=en.

2. Diniz CS, Grilo, Niy DY, Andrezzo HFA, Carvalho PCA, Salgado HO. A vaginaescola: seminário interdisciplinar sobre violência contra a mulher no ensino das profissões de saúde. Interface (Botucatu). 2016;20(56):253-9. doi: http:// dx.doi.org/10.1590/1807-57622015.0736.

3. Leal LM, Silva AAM, Dias MAB, Gama SGN, Rattner D, Moreira ME, et al. Birth in Brazil: national survey into labour and birth. Reprod Health. 2012;9:15. doi: https://doi.org/10.1186/1742-4755-9-15.

4. Wernet M, Bussadori JCC, Fabbro MRC, Silveira AL, Napoleão AA. Risco de paternidade ou maternidade prejudicada: um olhar ao ciclo gravídico puerperal, In: Herdman TH, Napoleão AA (organizadores) PRONANDA: Programa de atualização em diagnósticos de enfermagem: ciclo quatro. Porto Alegre: ArtmedPanamericana; 2016. p. 69-89.

5. Vargens OMC, Silva ACV, Progianti JM. Contribuição de enfermeiras obstétricas para consolidação do parto humanizado em maternidades no Rio de Janeiro-Brasil. Esc Anna Nery. 2017;21(1):e20170015. doi: https://doi. org/10.5935/1414-8145.20170015.
6. Nascimento RRP, Arantes SL, Souza EDC, Contrera L, Sales APA. Choice of type of delivery: factors reported by puerperal woman. Rev Gaúcha Enferm. 2015;36(spe):119-26. doi: https://doi.org/10.1590/1983-1447.2015.esp.56496.

7. Diniz SG, Salgado HO, Andrezzo HFA, Carvalho PGC, Carvalho PCA, Aguiar CA, et al. Abuse and disrespect in childbirth care as a public health issue in Brazil: origins, definitions, impacts on maternal health, and proposals for its prevention. J Hum Growth Dev. 2015;25(3):377-84. doi: https://doi.org/10.7322/ jhgd. 106080

8. Charon JM. Symbolic interactionism: an introduction, an interpretation, an integration. 10th ed. Englewood Cliffs: Prentice Hall; 2010.

9. Instituto Brasileiro de Geografia e Estatística [Internet]. Rio de Janeiro: IBGE; 2017- . São Carlos: panorama; [citado 2017 set 07]; [aprox. 2 telas]. Disponível em: https://cidades.ibge.gov.br/brasil/sp/sao-carlos/panorama.

10. Ministério da Saúde (BR). Datasus [Internet]. Brasilia: Ministério da Saúde; 2017- . Sistema de Informações sobre Nascidos Vivos: São Carlos-SP 2015; [citado 2017 set 10]; [aprox. 1 tela]. Disponivel em: http://tabnet.datasus.gov. br/cgi/tabcgi.exe?sinasc/cnv/nvsp.def.

11. Bardin L. Análise de conteúdo. São Paulo: Edições 70; 2011.

12. Tostes NA, Seidl EMF. Expectativas de gestantes sobre o parto e suas percepções acerca da preparação para o parto. Temas Psicol. 2016;24(2):681-93. doi: https://doi.org/10.9788/TP2016.2-15.

13. Domingues RMSM, Dias MAB, Nakamura-Pereira M, Torres JA, d'Orsi E, Pereira APE, et al. Cad Saúde Pública. 2014;30(Suppl.1):S101-S116. doi: https://doi. org/10.1590/0102-311X00105113.

14. Montoya DIG, Mazuelo EMG, López (PH. Experiencia de las mujeres durante el trabajo de parto y parto. Av Enferm. 2015;33(2):271-81. doi: https://doi. org/10.15446/av.enferm.v33n2.42279.

15. Boryri T, Noori NM, Teimori A, Yaghonobinia F. The perception of primiparous mothers of comfortable resources in labor pain (a qualitative study). Iran J Nurs Midwifery Res. 2016;21(3):239-46. doi: https://doi.org/10.4103/1735-9066.180386.

16. Nakano AR, Bonan C, Teixeira LA. 0 trabalho de parto do obstetra: estilo de pensamento enormalização do"parto cesáreo" entre obstetras. Physis. 2017;27(3):41532. doi: https://doi.org/10.1590/50103-73312017000300003.

17. Raspantini PR, Miranda MJ, Silva ZP, Alencar GP, Diniz SG, Almeida MF. 0 impacto do tipo de hospital e tipo de parto sobre a idade gestacional ao nascer no Município de São Paulo, 2013-2014. Rev Bras Epidemiol. 2016;19(4):878-82. doi: https://doi.org/10.1590/1980-5497201600040016.

18. d'Orsi E, Brüggemann OM, Diniz CSG, Aguiar JM, Gusman CR, Torres JA, AnguloTuesta $A$, et al. Desigualdades sociais e satisfação das mulheres com 0 atendimento ao parto no Brasil: estudo nacional de base hospitalar. Cad Saúde Pública. 2014;30(Supp.1):S154-S168. doi: https://doi.org/10.1590/0102-311X00087813.

19. Sena LM, Tesser CD. Violência obstétrica no Brasil e o ciberativismo de mulheres mães: relato de duas experiências. Interface (Botucatu). 2017;21(60):209-20. doi: https://doi.org/10.1590/1807-57622015.0896.

20. Ministério da Saúde (BR). Diretrizes Nacionais de Assistência ao Parto Normal: versão resumida. Brasília (DF); 2017.

Recebido: 23.10 .2017

Aprovado: 31.07.2018 